CLINICAL STUDY

\title{
Hypoparathyroidism and autoimmunity in the 22q11.2 deletion syndrome
}

\author{
Kari Lima ${ }^{1,2,3}$, Tore G Abrahamsen ${ }^{3,4}$, Anette Bøe Wolff ${ }^{5}$, Eystein Husebye ${ }^{5,6}$, Mohammad Alimohammadi ${ }^{7}$, \\ Olle Kämpe $^{7}$ and Ivar Følling ${ }^{1,2}$ \\ ${ }^{1}$ Department of Endocrinology, Division of Medicine, Akershus University Hospital, N-1478 Lørenskog, Norway, ${ }^{2}$ Institute of Clinical Medicine, Akershus \\ University Hospital, University of Oslo, Oslo, Norway, ${ }^{3}$ Department of Paediatrics, Oslo University Hospital, Rikshospitalet, Oslo, Norway, ${ }^{4}$ Institute of \\ Clinical Medicine, University of Oslo, Oslo, Norway, ${ }^{5}$ Institute of Medicine, University of Bergen, Bergen, Norway, ${ }^{6}$ Department of Medicine, Haukeland \\ University Hospital, Bergen, Norway and ${ }^{7}$ Department of Medical Sciences, Uppsala University, Uppsala, Sweden
}

(Correspondence should be addressed to K Lima at Department of Endocrinology, Division of Medicine, Akershus University Hospital; Email: kari.lima@medisin.uio.no)

\begin{abstract}
Objective: To characterize the endocrine and autoimmune disturbances with emphasis on parathyroid dysfunction in patients with 22q11.2 deletion syndrome (22q11.2 DS).

Design: In this nationwide survey; 59 patients (age 1-54 years) out of 86 invited with a 22q11.2 DS were recruited through all the genetic institutes in Norway.

Methods: Data was collected from blood tests, medical records, a physical examination and a semistructured interview. We registered autoimmune diseases and measured autoantibodies, hormone levels and HLA types.

Results: Twenty-eight (47\%) patients had hypoparathyroidism or a history of neonatal or transient hypocalcemia. Fifteen patients had neonatal hypocalcemia. Fourteen patients had permanent hypoparathyroidism including seven (54\%) of those above age 15 years. A history of neonatal hypocalcemia did not predict later occurring hypoparathyroidism. Parathyroid hormone levels were generally low indicating a low reserve capacity. Twenty-eight patients were positive for autoantibodies. Six $(10 \%)$ persons had developed an autoimmune disease, and all were females $(P<0.02)$. Hypoparathyroidism correlated with autoimmune diseases $(P<0.05)$, however, no antibodies were detected against the parathyroid glands.

Conclusions: Hypoparathyroidism and autoimmunity occur frequently in the 22q11.2 DS. Neonatal hypocalcemia is not associated with later development of permanent hypoparathyroidism. Hypoparathyroidism may present at any age, also in adults, and warrants regular measurement of calcium levels. Hypoparathyroidism and autoimmunity occur frequently together. Our findings of autoimmune diseases in $10 \%$ of the patients highlight the importance of stringent screening and follow-up routines.
\end{abstract}

European Journal of Endocrinology 165 345-352

\section{Introduction}

In 1965, DiGeorge (1) described three neonates with severe immunodeficiency, thymus aplasia, and neonatal hypocalcemia due to aplasia of the parathyroid glands. Later, cardiac anomalies were added to the phenotype called DiGeorge syndrome. In 1992, it was discovered that the majority of these patients had a microdeletion on chromosome 22q11.2 (2). This is now recognized as the most common microdeletion syndrome in humans with an incidence of $\sim 1: 4000$ live births (3).

Hypoparathyroidism in the 22q11.2 deletion syndrome (22q11.2 DS) patients is often transient and resolves after the neonatal period, but may manifest itself later in life as episodes of hypocalcemia during stress such as infectious disease, surgery or pregnancy.
In some patients permanent hypoparathyroidism develops (4-6). There is limited knowledge about the pathogenesis and natural course of hypoparathyroidism, but a developmental defect may explain why the parathyroid glands are small and have limited capacity of parathyroid hormone (PTH) production (7). Alternatively, an autoimmune destruction or inhibition of function could also be operational, since individuals with the 22q11.2 DS are prone to autoimmune diseases $(8,9)$, particularly cytopenias $(10-12)$, juvenile idiopathic arthritis (8), and celiac disease (13). One study reported autoimmune disorders or detectable autoantibodies in 33\% of the patients (9).

Patients with 22q11.2 DS have an immune defect caused by thymic hypoplasia. Thymic T cell diversity (14) and output is reduced (15) with reduced absolute 
numbers of naïve CD3CD45RA (15) and regulatory CD3CD4CD25 T cells (16). B cells can also be affected (17) with a tendency for immunoglobulin deficiencies (18-20). These alterations are not severe, but could at least partly explain an increased frequency of autoimmune disorders.

Autoimmunity against the parathyroid is rare and reports are scarce. Moreover, both blocking and stimulating antibodies against the calcium sensing receptor have been reported $(21,22)$, the latter giving rise to hypoparathyroidism. Recently, a novel parathyroid autoantigen NACHT leucine-rich-repeat protein 5 (NALP5) was reported in patients with autoimmune polyendocrine syndrome type 1 (APS1) (23). Whether these autoantibodies are involved in DiGeorge syndrome is not known.

The aim of this investigation was to conduct a nationwide study on endocrine and autoimmune disturbances in patients with 22q11.2 DS, with special emphasis on parathyroid dysfunction.

\section{Patients and methods}

\section{Patients}

Through the genetic institutions in Norway, 86 patients diagnosed with a 22q11.2 DS by fluorescent in situ hybridization (FISH) from 1993 to 2006, were invited to participate in a nationwide survey (24). Sixty-two patients agreed to participate, two dropped out before the study started due to medical reasons. One patient who refused blood testing was included in the clinical part only. Fifty-nine patients, 31 females and 28 males, median age 9 years (range 1-54), from all parts of Norway were included. The diagnosis was verified using a multiplex ligation-dependent probe amplification assay (24). All patients were observed at the Pediatric Outpatient Clinic at Rikshospitalet, Oslo University Hospital between 2005 and 2007. The study was approved by the Regional Committee for Research Ethics and the Norwegian Data Inspectorate. Before inclusion, written informed consent was obtained from the participants or their parents.

\section{Clinical data}

By using a semi-structured interview and scrutinizing the medical records we identified neonatal hypocalcemia (from birth to 1 month of age) and later hospitalizations due to hypocalcemia. Hypoparathyroidism was defined as S-calcium below the reference range with inappropriately low PTH concentration. Since hypocalcemia is the most potent stimulus of PTH secretion; a low or even normal serum PTH concentration in a patient with hypocalcemia is a strong evidence of hypoparathyroidism (25) in the presence of elevated phosphate levels and the absence of kidney failure. Celiac disease was verified by duodenal biopsies.
Autoimmune and related diseases were registered based on typical biochemical findings and clinical evaluation.

\section{Clinical chemistry}

We measured the levels of total calcium (2.15$2.55 \mathrm{mmol} / \mathrm{l}$; Elecsys Modular PE, Roche), ionized Calcium (1.14-1.32 mmol/l; ABL, radiometer, Diamond Diagnostics, Holliston, MA, USA), intact PTH (Immulite 2000, Luminometer, Siemens, Munich, Germany), 25-hydroxyvitamin D (37-131 nmol/l), and 1,25-dihydroxyvitamin D (72-216 pmol/l in children, 42-169 pmol/l in adults; competitive RIA, DiaSorin, Stillwater, MN, USA). Other hormone measurements were: TSH, free thyroxine (Modular PE, Roche), IGF1 (Immulite 2000, Luminometer), IGF binding protein 3 (IGFBP3; ELISA, Diagnostic System Laboratories, TX, USA), ACTH (Berilux analyzer 250, B.R.A.M.H.S. Diagnostica GmbH, Berlin, Germany, luminometer chemoluminiscence immunoassay), cortisol, LH, FSH, and estradiol/testosterone (Modular PE, Roche). Immunoglobulins were measured and compared with age-related standards (26). DRB1 and DQB1 genotyping was performed with a PCR-based sequence-specific oligonucleotide probe system at four-digit resolution as described elsewhere (27). The DQA1 alleles and HLA-DRB1-DQA1-DQB1 haplotypes were deduced based on known patterns of linkage disequilibrium in the Norwegian population. Exon 3 was not typed, and so we did not distinguish DQB1*0201 from *0202.

\section{Antibody assays}

Autoantibodies against organ-specific autoantigens: 21-hydroxylase $(210 \mathrm{H}$; <48), $17 \alpha$-hydroxylase $(17 \mathrm{OH}$; $<102$ ), side-chain cleavage enzyme (SCC; <184), glutamic acid decarboxylase $65(<122)$, tryptophan hydroxylase $(<84)$, tyrosine hydroxylase $(\mathrm{TH} ;<103)$, protein tyrosine phosphatase $(<77)$, NALP5 (23), aromatic L-amino acid decarboxylase $(<89)$, and interferon $\omega(<200)$ were measured using RIA based on the proteins expressed by in vitro transcription and translation $(28,29)$. We also measured antibodies against; nucleus (anti-nuclear antibodies (ANA), indirect immunofluorescence (IIF); <32) performed on a human epithelial-2 cell substrate, and if positive ANA against double-stranded DNA (ELISA); anti-smooth muscle (ASM; <20), mitochondria (IIF, <20); parietal cells (IIF, pos 1:20); thyroid peroxidase (TPO, a modified ELISA; 1-99 IU/ml); islet cells antibodies (IIF, <4); intrinsic factor $(0.0-5.9 \mathrm{U} / \mathrm{ml})$; thyroglobulin $(\mathrm{Tg})$ (ELISA) (1-99 IU/ml); tissue transglutaminase (IgA, ELISA; $0.0-4.9 \mathrm{U} / \mathrm{ml})$, and thyroid-stimulating antibodies (TSAb; 1.0-2.0 IU/l), and rheumatoid factor (RF; latex $\operatorname{IgA}$ ) an antibody against the Fc portion of IgG $(1-8 \mathrm{AU} / \mathrm{ml})$. 
Table 1 Clinical features of 60 patients with 22q11.2 deletion syndrome.

\begin{tabular}{lc}
\hline Clinical characteristics & $\boldsymbol{n}(\%)$ \\
\hline Congenital cardiac anomalies & $39(65)$ \\
Frequent infections before 7 years & $47(78)$ \\
Skeletal deformities & $36(60)$ \\
Urinary deformities & $4(7)$ \\
Operated cleft lip or palate & $20(33)$ \\
Feeding difficulties & $38(63)$ \\
Speech difficulties & $50(83)$ \\
Learning difficulties & $58(97)$ \\
\hline
\end{tabular}

\section{Statistical analysis}

SPSS for Windows release 14.0 (Chicago, IL, USA) was used for the statistical descriptive analyses of the data. Data are expressed as median (range). We used t-test for (log transformed) PTH levels versus the (log transformed) reference values. To evaluate possible differences in frequency of autoimmune diseases in patients with or without hypoparathyroidism $\chi^{2}$ tests with Yates correction were performed. We also used $\chi^{2}$ tests to look at differences in frequency of autoantibodies detected in patients with and without hypoparathyroidism and presence of neonatal hypocalcemia versus later occurring hypoparathyroidism.

\section{Results}

\section{Neonatal hypocalcemia}

The patients' main clinical features are summarized in Table 1 and have also been reported elsewhere $(15,24)$. Neonatal hypocalcemia was registered in the medical records of 15 of 59 patients (25\%). Blood tests had been taken due to symptoms such as quivering, convulsions, or hypotonia in nine patients or as a routine check in six patients with suspected 22q11.2 DS due to cardiac anomalies (Table 2). Two of the 15 patients had permanent hypocalcemia, three reverted to normocalcemia, but hypoparathyroidism occurred at ages 2,10 , and 26 years respectively. The remaining ten patients had no further registered episode of hypocalcemia from birth to the study examination.

\section{Hypoparathyroidism}

Fourteen of the 59 patients $(24 \%)$ had hypoparathyroidism at examination including five of the patients with neonatal hypocalcemia described earlier (two permanent and three recurrent; Table 2). One had experienced an earlier episode of transient hypocalcemia during cardiac surgery before permanent hypoparathyroidism was diagnosed. In addition, four other patients had

Table 2 Characteristics of hypocalcemia and hypoparathyroidism in 28 patients with $22 q 11.2$ deletion syndrome.

\begin{tabular}{|c|c|c|c|c|c|}
\hline Pat. no. & $\begin{array}{l}\text { Age at } \\
\text { study }\end{array}$ & Sex & $\begin{array}{l}\text { Neonatal hypocalcemia/ } \\
\text { symptoms }\end{array}$ & $\begin{array}{l}\text { Episodes of } \\
\text { hypocalcemia }^{a}\end{array}$ & $\begin{array}{l}\text { Later } \\
\text { hypoparathyroidism/ } \\
\text { symptoms }^{\text {a }}\end{array}$ \\
\hline 2 & 13 & $\mathrm{~F}$ & & & Screening $^{\mathrm{b}}(13)$ \\
\hline 3 & 13 & $M$ & Screening & & \\
\hline 4 & 38 & $\mathrm{~F}$ & & & Convulsion (32) \\
\hline 6 & 6 & $\mathrm{~F}$ & Screening & & \\
\hline 11 & 8 & $\mathrm{~F}$ & & Screening (6) & Treated (possible) \\
\hline 13 & 2 & $\mathrm{~F}$ & Quivering & & \\
\hline 14 & 9 & $\mathrm{~F}$ & & & Convulsion (4) \\
\hline 16 & 44 & $M$ & & & Listlessness (42) \\
\hline 18 & 17 & $M$ & & & Screening $^{\mathrm{b}}(17)$ \\
\hline 20 & 16 & $\mathrm{M}$ & & Screening (4 months) & \\
\hline 22 & 25 & $\mathrm{~F}$ & & & Screening (22) \\
\hline 23 & 3 & $\mathrm{~F}$ & & Screening (3) & \\
\hline 25 & 4 & $\mathrm{M}$ & Screening & & Permanent from birth \\
\hline 26 & 4 & $\mathrm{~F}$ & Convulsion & & \\
\hline 29 & 14 & $M$ & Quivering & & \\
\hline 30 & 1 & $\mathrm{~F}$ & Screening & & \\
\hline 31 & 7 & $\mathrm{M}$ & Screening & & Permanent from birth \\
\hline 32 & 9 & $\mathrm{~F}$ & & Related to surgery (4) & \\
\hline 35 & 38 & $\mathrm{~F}$ & & & Screening (35) \\
\hline 37 & 11 & $\mathrm{M}$ & Hypotonia & & \\
\hline 38 & 29 & $\mathrm{~F}$ & Quivering & & Screening (26) \\
\hline 41 & 18 & $\mathrm{~F}$ & & & Screening (14) \\
\hline 43 & 9 & $M$ & & Related to surgery (2) & Screening $^{b}(9)$ \\
\hline 46 & 3 & $M$ & Quivering & & \\
\hline 48 & 10 & $\mathrm{~F}$ & Convulsion & & Screening $^{\mathrm{b}}(10)$ \\
\hline 51 & 5 & $\mathrm{~F}$ & Hypotonia & & \\
\hline 53 & 2 & $M$ & Quivering & & \\
\hline 60 & 2 & $\mathrm{M}$ & Screening & & Screening $^{\mathrm{b}}(2)$ \\
\hline
\end{tabular}

aThe age in years at the start of hypocalcemia or hypoparathyroidism is given in parenthesis.

biagnosed in this study. 


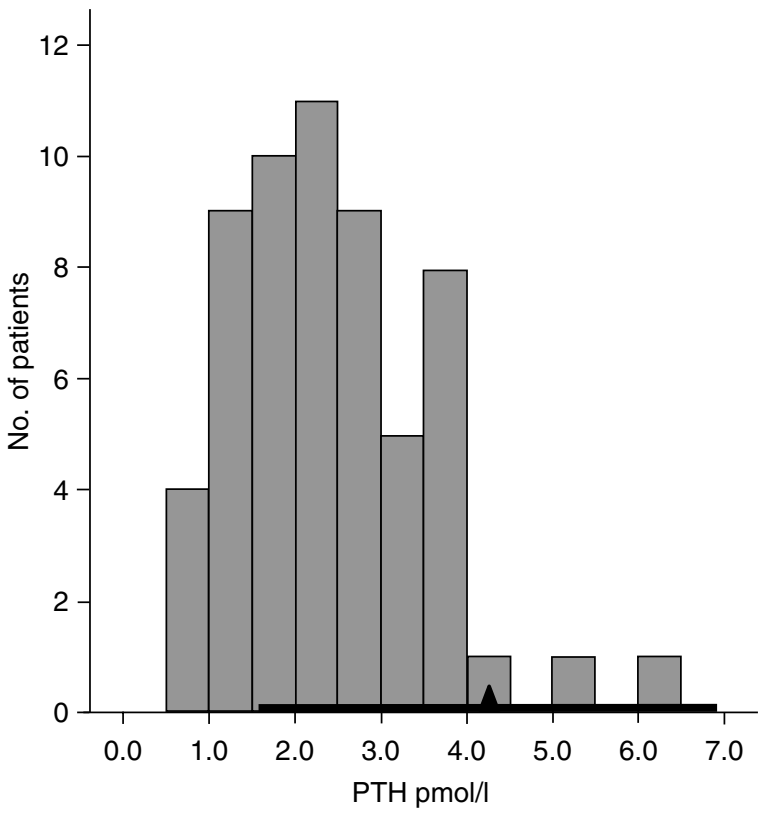

Figure 1 PTH levels in 59 patients with 22q11.2 DS. Histogram of PTH values in 59 patients. The reference interval $(1.6-6.9 \mathrm{pmol} / \mathrm{l})$ is marked with a thick black line. The filled triangle marks the middle of the reference interval.

experienced one or more episodes of hypocalcemia during surgery, infection or follow-up. The classification of transient or permanent hypoparathyroidism proved difficult in one patient (no. 11, Table 2) because calcium and vitamin D supplementation was started quickly after hypocalcemia was discovered.

Altogether 28 (47\%) patients had neonatal, transient or permanent hypocalcemia at some point during follow-up (Table 2). Seven (54\%) of 13 patients above 15 years of age had hypoparathyroidism. The occurrence of hypoparathyroidism after the age of 15 was independent of the occurrence of neonatal hypocalcemia $(P>0.2)$.

The PTH levels at examination, were generally low (Fig. 1) with a median value of $2.3 \mathrm{pmol} / \mathrm{l}$ (range $<0.6-6.4)$ compared with the reference values $(P<0.001)$. Fourteen $(24 \%)$ patients had PTH below the lower reference value, $57(97 \%)$ patients were in the lower half of the reference interval or below, demonstrating that the PTH production is impaired in these patients. The PTH levels tended to decline with increasing age (data not shown).

The median serum calcium concentration was $2.32 \mathrm{mmol} / \mathrm{l}$ (range $1.85-2.56 \mathrm{mmol} / \mathrm{l}$ ), leaving most patients within the normal range, indicating that treatment with calcium supplements alone or combination with vitamin $\mathrm{D}$, was adequate.

Vitamin D levels were measured in 55 patients. All had 1,25-dihydroxyvitamin D in the normal range. Six patients had low levels of 25-hydroxyvitamin D, of whom five were normocalcemic and one hypocalcemic.

\section{Autoimmune and related clinical diseases}

Six patients $(10 \%)$ had autoimmune diseases (Table 3), all were females $(P<0.02)$. Two patients had celiac disease, diagnosed at age 6 and 11 years, three had hypothyroidism diagnosed at 20,22, and 26 years of age (Table 3), and one was also diagnosed with pernicious anemia and atrophic gastritis. Finally, one patient had idiopathic thrombocytopenic purpura at age 6 years and seronegative arthritis at age 15, diagnosed as psoriatic arthritis. These latter four patients also suffered from hypoparathyroidism that was significantly more frequent in patients with autoimmune disease than in those without $(P<0.05)$. In addition, one other patient had severe psoriasis, one had Raynaud phenomenon, and two had asthma.

\section{Growth and hormone deficiencies}

Eight patients (14\%) had a birth weight below the 2.5th percentile and $12(20 \%)$ below the 5th percentile according to gestational age using Norwegian standards (30). Seventeen $(29 \%)$ of the patients were below the 2.5th percentile of height. Only one adult patient had low levels of IGF1 and IGFBP3 compared with age references. No patients had low cortisol and high ACTH or elevated $\mathrm{HbAlc}$ and none of the patients had hypogonadism. We did not diagnose any new cases with hypothyroidism.

\section{Autoantibodies, immunoglobulins, and HLA}

Sera from $28(48 \%)$ of the 58 patients analyzed, had detectable autoantibodies against a wide range of autoantigens (Table 3). However, no serum showed positivity for antibodies against NALP5, a parathyroid autoantigen. Most sera displayed low antibody indices. The most frequent autoantibodies were ASM $(n=7)$, TH $(n=7)$, and ANA $(n=6)$. In the ANA-positive group, two patients aged 5 and 8 years, had high titers $(2560$ and 512). None had antibodies against DNA. We also found autoantibodies against endocrine glands. In particular, the steroidogenic enzymes $210 \mathrm{H}, 17 \mathrm{OH}$, and SCC were targeted in nine patients (Table 3). Five of the patients with autoantibodies to $210 \mathrm{H}$ also had autoantibodies against one or two other adrenal enzymes. All these patients had normal ACTH and cortisol levels.

Antibodies against TPO were less abundant and found in two of three patients with hypothyroidism. The patient without anti-TPO and hypothyroidism had the diagnosis for 16 years. Anti-Tg was positive in four patients; three of whom had normal thyroid function. There was no difference in autoantibody frequency in patients with or without hypoparathyroidism.

One 10-year-old patient had IgA deficiency. The patients with celiac disease all had the associated HLA DRB $1 * 03-\mathrm{DOB} 1 * 02$ haplotype. The patients with other 
Table 3 Autoantibodies and autoimmune diseases in 28 patients with 22q11.2 deletion syndrome.

\begin{tabular}{|c|c|c|c|c|}
\hline $\begin{array}{l}\text { Pat. } \\
\text { no. }\end{array}$ & $\begin{array}{c}\text { Age at } \\
\text { examination } \\
\text { (years) }\end{array}$ & Sex & Autoantibodies (titers, indices, or units) & $\begin{array}{l}\text { Manifestations } \\
\text { (age in years at diagnosis) }\end{array}$ \\
\hline 1 & 4 & $\mathrm{~F}$ & TH (136), ASM (20) & Raynaud (4) \\
\hline 3 & 13 & $\mathrm{M}$ & TH (168) & \\
\hline $4^{\mathrm{a}}$ & 38 & $\mathrm{~F}$ & PC (64), IF (8 U/ml), 17OH (102), GAD (1329), ICA (16) & $\begin{array}{l}\text { Hypothyroidism (22), pernicious } \\
\text { anemia (31), atrophic gastritis (33) }\end{array}$ \\
\hline 9 & 3 & $\mathrm{M}$ & ASM (40), TH (106), 170H (189) & \\
\hline 10 & 6 & $\mathrm{~F}$ & $\operatorname{ASM}(20)$, TSAb $(3 \mathrm{IU} / \mathrm{I})$ & \\
\hline 11 & 8 & $\mathrm{~F}$ & ANA (512), ASM (64), $210 \mathrm{OH}(52), 17 \mathrm{OH}(108)$, IA2 (428) & \\
\hline 12 & 15 & $\mathrm{~F}$ & ANA (32), ASM (64) & \\
\hline 13 & 2 & $\mathrm{~F}$ & ANA (128), TH (103) & \\
\hline $14^{\mathrm{a}}$ & 9 & $\mathrm{~F}$ & ANA (32) & \\
\hline $16^{\mathrm{a}}$ & 44 & $\mathrm{M}$ & $\mathrm{TH}(192)$ & \\
\hline 20 & 16 & $\mathrm{M}$ & IA2 (85), TH (151) & \\
\hline $22^{\mathrm{a}}$ & 25 & $\mathrm{~F}$ & ANA (32), TPO (219 IU/ml), TG (232 IU/ml) & Hypothyroidism (20) \\
\hline 23 & 3 & $\mathrm{M}$ & $210 \mathrm{H}(82)$ & \\
\hline 24 & 5 & $\mathrm{~F}$ & TG (114 IU/ml), SSC (237), $210 \mathrm{OH}(146), 17 \mathrm{OH}(185)$ & \\
\hline 29 & 14 & $\mathrm{~F}$ & ICA (4) & \\
\hline 32 & 9 & $\mathrm{~F}$ & $210 \mathrm{H}(74)$ & \\
\hline 33 & 11 & $\mathrm{M}$ & $\mathrm{TH}(113)$ & \\
\hline 34 & 7 & $\mathrm{~F}$ & $170 \mathrm{H}(104), \mathrm{IA} 2(78)$ & \\
\hline 37 & 10 & $\mathrm{~F}$ & TG $(259 \mathrm{IU} / \mathrm{ml}), \mathrm{PC}(20)$ & \\
\hline $38^{\mathrm{a}}$ & 29 & $\mathrm{~F}$ & TPO $(636 \mathrm{lU} / \mathrm{ml})$ & Hypothyroidism (29) \\
\hline $41^{\mathrm{a}}$ & 18 & $\mathrm{~F}$ & & $\begin{array}{l}\text { Idiopathic thrombocytopenic purpura } \\
\text { (6), psoriasis arthritis (15) }\end{array}$ \\
\hline 46 & 3 & $\mathrm{M}$ & $\mathrm{TG}(117 \mathrm{IU} / \mathrm{ml}), 17 \mathrm{OH}(154)$ & \\
\hline 47 & 14 & $\mathrm{~F}$ & PC (320), tTG ${ }^{b}$ & Celiac disease (6) \\
\hline $48^{a}$ & 10 & $\mathrm{~F}$ & $210 \mathrm{H}(49)$ & IgA deficiency (10) \\
\hline 50 & 2 & $\mathrm{~F}$ & ASM (20) & \\
\hline 51 & 5 & $\mathrm{~F}$ & ANA (2560) & \\
\hline 56 & 10 & $\mathrm{M}$ & ASM (20) & \\
\hline 58 & 11 & $\mathrm{~F}$ & tTG $(13 \mathrm{U} / \mathrm{ml})$ & Celiac disease (11) \\
\hline
\end{tabular}

ANA, anti-nuclear antibodies ( $<32)$; IA2, protein tyrosine phosphatase $(<77)$; ASM, anti-smooth muscle $(<20)$; GAD, glutamic acid decarboxylase 65 ( $<122)$; ICA, islet cells antibodies $(<4)$; IF, intrinsic factor $(0.0-5.9 \mathrm{U} / \mathrm{ml}) ; 17 \mathrm{OH}, 17 \alpha$-hydroxylase $(<102) ; 21 \mathrm{OH}, 21$-hydroxylase $(<48)$; PC, parietal-cells $(<20)$; SCC, side-chain cleavage enzyme (<184); TG, thyroglobulin (1-99 IU/ml); tTG, tissue transglutaminase $(0.0-4.9 \mathrm{U} / \mathrm{ml}) ; \mathrm{TH}$, tyrosine hydroxylase ( $<103)$; TPO, thyroid peroxidase (1-99) IU/ml); TSAb, thyroid-stimulating antibodies (1.0-2.0 IU/I). The reference values in parenthesis. Reciprocal titer unless otherwise stated.

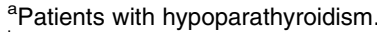

${ }^{\mathrm{b}}$ No detectable tTG, the patient had been treated with gluten-free diet for 8 years.

autoimmune manifestations did not demonstrate any clear associations to HLA haplotypes normally associated with these disorders in the Norwegian population (data not shown). However, the limited number of patients with evidence of autoimmunity does not allow for any firm conclusions to the role of HLA genotypes.

\section{Discussion}

We have conducted a broad nationwide cross-sectional study of 59 patients with 22q11.2 DS to characterize endocrine and autoimmune disturbances with emphasis on parathyroid dysfunction. We actively invited all patients in Norway with a diagnosis of 22q11.2 deletion confirmed by FISH to participate, taking advantage of the relatively small and surveyable population of the country. Our cohort is probably representative for the diagnosed Norwegian 22q11.2 DS patient population, but there is an uncertainty related to the fact that 26 diagnosed cases did not participate for unknown reasons. However, with an estimated incidence of 1:4000, a considerable number of patients remain to be identified, just as for other published 22q11.2 DS cohorts. Some of the seriously affected individuals included in this study were diagnosed late, indicating that the phenotypic variation is also great among the undiagnosed individuals. Other reported studies may be biased since they originate from specialized clinics $(9,18)$.

Forty-seven percent of the patients had hypoparathyroidism or a history of neonatal or transient hypocalcemia. There is a great variety in the clinical presentation and severity of hypocalcemia and hypoparathyroidism in our patients. Neonatal hypocalcemia is one of the cardinal symptoms of DiGeorge syndrome, however, its prevalence in 22q11.2 DS is difficult to establish. Our patients were only tested when they had symptoms of hypocalcemia or clinical suspicion of the syndrome. Thus, the occurrence of neonatal hypocalcemia may be underestimated. Still, it is probable that the patients with most pronounced hypocalcemia developed symptoms and were tested. This is supported by documented normal calcium levels in three neonates 
tested due to quivering. To establish the overall prevalence of neonatal hypocalcemia, systematic screening is required.

There is little, reported follow-up data about the association between neonatal hypocalcemia and later parathyroid gland function in these patients. In one previous report of 61 patients with 22q11.2 DS 20 of them had neonatal and five developed permanent hypoparathyroidism from birth (31). In our study, only two patients had permanent hypoparathyroidism from birth. In total five of 15 patients with neonatal hypocalcemia got later permanent hypoparathyroidism versus nine of 44 patients without neonatal hypocalcemia. There was no significant association, even in those neonates with severe symptoms in the neonatal period (Table 2). Therefore the occurrence of neonatal hypocalcemia could not predict later permanent hypoparathyroidism.

Hypoparathyroidism can be diagnosed at all ages in patients with $22 \mathrm{q} 11.2 \mathrm{DS}$, and $54 \%$ of the patients above 15 years had hypoparathyroidism (Table 2). In our study, four adult patients were diagnosed with 22q11.2 DS due to hypoparathyroidism (24). We demonstrate that hypoparathyroidism can be diagnosed at all ages in patients with 22q11.2 DS. Mild hypocalcemia without symptoms may last for many years. This is also reflected in the low levels of PTH (Fig. 1) indicating that the PTH reserve is limited in the 22q11.2 DS. Consequently, patients should be screened for hypocalcemia at regular intervals to prevent symptoms and complications to hypocalcemia, and 22q11.2 DS should always be considered as a cause of hypoparathyroidism in persons without a history of thyroid surgery.

Studies have shown an association between immunodeficiency syndromes in childhood and the later development of autoimmune disorders (32). IgA deficiency, the most common primary immunodeficiency with a prevalence of 1 per 500-700 among Europeans, is associated with both systemic and organspecific autoimmune diseases (33). The prevalence of IgA deficiency in our study was one of 59 in contrast to one of eight in two previous reports $(9,18)$, which might be influenced by their selection of patients.

We found autoantibodies in 28 patients $(47 \%)$ especially ANA, which is even higher than in an earlier report on autoimmunity in 22q11.2 DS (9). Only two patients aged 5 and 8 years, had high titers (2560 and 512) of ANA, and none had anti-DNA. This is in contrast to absence of ANA or RF after thymectomy during cardiac operations in non-syndromic infants (34). Most of the patients had ANA and ASM in very low titers. The prevalence of positive ANA among healthy individuals varies depending on age and sex and is reported in 30-40\% of blood donors (35). Children with positive ANA and without clinical signs of an autoimmune disease have been found to have a minimal risk of developing an autoimmune disease despite the persistently positive ANA (36). Only follow-up studies can reveal if ANA or ASM positivity is an early marker of autoimmune disease in 22q11.2 DS patients.

We also detected autoantibodies against enzymes in the adrenal gland in sera from nine patients. This is of particular interest, as APS1 (37) and 22q11.2 syndrome both have defects in thymic function. All patients with adrenal autoantibodies had normal ACTH and cortisol levels, and the autoantibody indices were lower than observed in most patients with primary autoimmune adrenal insufficiency (38) or APS1. Among relatives of patients with an organ-specific autoimmune disease the presence of autoantibodies against the adrenal gland predicts developing autoimmune adrenal disease (39). The high frequency of low titers of autoantibodies (Table 3) may indicate an impaired immune system in the 22q11.2 DS patients (15).

An autoimmune disease was found in six patients (10\%), of whom four in addition suffered from permanent hypoparathyroidism. This association reaches statistical significance $(P<0.05)$, but patient numbers are low. There are few studies including adult 22q11.2 DS patients, and our data indicate the importance of including screening for autoimmunity when planning follow-up routines. Hypothyroidism was diagnosed in three adult patients (Table 2). In addition, one patient had positive TSAb, but no hyperthyroidism. Autoimmune thyroid disease found in three of ten $(30 \%)$ patients above the age of 17 years is a slightly higher incidence than in a previous report of 78 adult 22q11 DS patients (40) and also higher than in the general population in Norway (5\%) (41). Two patients had celiac disease, diagnosed at age 6 and 11 years. This is more frequent than in an earlier report (13) and may warrant screening of celiac disease in 22q11.2 DS patients. We found one patient with idiopathic thrombocytopenic purpura and seronegative arthritis, diagnosed to be psoriatic arthritis, in contrast to earlier studies reporting increased prevalence of juvenile idiopathic arthritis (42). These results warrant a study on a much larger population of patients with 22q11.2 DS since many different autoimmune diseases may occur.

The pathogenesis of the reduced parathyroid capacity could be an autoimmune destruction or congenital hypoplasia that becomes evident as the demand for PTH secreting capacity increases with age. None of the 22q11.2 DS patients had parathyroid (NALP5) antibodies, but this does not exclude a low-grade ongoing autoimmune process without detectable antibodies, since NALP5 so far has been shown to be a marker for autoimmune hypoparathyroidism in APS1 patients only. A recent report finds an association between hypoparathyroidism and clinically significant $\mathrm{T}$ cell immunodeficiency in the 22q11.2 DS (43). We have earlier reported on the thymic function of 43 of the patients (15). Only one had clinically significant tendency to serious infections when tested. However, our study is too small for any conclusions to be made on 
a possible connection between low thymic output and autoimmune disease or hypoparathyroidism. Also, age is a confounding factor since the prevalence of autoimmunity and hypoparathyroidism increases and thymic function declines with increasing age.

It would be expected that the same class II major histocompatibility complex susceptibility genes that confer risk for multiple autoimmune diseases in the general population might be more frequent in $22 \mathrm{q} 11.2$ DS patients with an autoimmune manifestation. Sullivan et al. (42) found HLA alleles associated with higher risk of juvenile idiopathic arthritis in three of three 22q11.2 DS patients. However, the limited number of patients with evidence of autoimmunity does not allow for any firm conclusions to the role of HLA genotypes. We failed to show a correlation between HLA alleles and autoimmunity, but we cannot exclude the possibility due to a lack of statistical power.

In conclusion, hypoparathyroidism and autoimmunity occur frequently in the 22q11.2 DS. Neonatal hypocalcemia is not associated with later development of permanent hypoparathyroidism. Hypoparathyroidism may be transient or permanent and occur at any age. Our findings highlight the importance of stringent screening and follow-up routines of these patients. Hypoparathyroidism and autoimmunity occur frequently together. A high frequency of adrenal autoantibodies was detected, but evidence of a specific autoimmune response against the parathyroid glands was not found.

\section{Declaration of interest}

The authors declare that there is no conflict of interest that could be perceived as prejudicing the impartiality of the research reported.

\section{Funding}

This work was supported by Akershus University Hospital and the Regional Health Authorities of South-Eastern (grant number 2759161) and the Regional Health Authorities of Western Norway.

\section{Acknowledgements}

We thank all the patients who participated in this study. We also want to thank Prof. Dag E Undlien and his co-workers at Department of Medical Genetics, Oslo University Hospital, Ullevål for preparing and analyzing the HLA data and the Hormone Laboratory, Endocrine Centre, Oslo University Hospital for analyzing the vitamin D levels.

\section{References}

1 DiGeorge AM. Discussion on a new concept of the cellular basis of immunity. Journal of Pediatrics 196567 907-908. (doi:10.1016/ S0022-3476(65)81796-6)

2 Scambler PJ, Kelly D, Lindsay E, Williamson R, Goldberg R, Shprintzen R, Wilson DI, Goodship JA, Cross IE \& Burn J. Velocardio-facial syndrome associated with chromosome 22 deletions encompassing the DiGeorge locus. Lancet 1992339 1138-1139. (doi:10.1016/0140-6736(92)90734-K)
3 Botto LD, May K, Fernhoff PM, Correa A, Coleman K, Rasmussen SA, Merritt RK, O'Leary LA, Wong LY, Elixson EM, Mahle WT \& Campbell RM. A population-based study of the 22q11.2 deletion: phenotype, incidence, and contribution to major birth defects in the population. Pediatrics 2003112 101-107. (doi:10.1542/peds.112.1.101)

4 Adachi M, Tachibana K, Masuno M, Makita Y, Maesaka H, Okada T, Hizukuri K, Imaizumi K, Kuroki Y, Kurahashi H \& Suwa S. Clinical characteristics of children with hypoparathyroidism due to 22q11.2 microdeletion. European Journal of Pediatrics 1998157 34-38. (doi:10.1007/s004310050762)

5 Cuneo BF, Langman CB, Ilbawi MN, Ramakrishnan V, Cutilletta A \& Driscoll DA. Latent hypoparathyroidism in children with conotruncal cardiac defects. Circulation 199693 1702-1708.

6 Maalouf NM, Sakhaee K \& Odvina CV. A case of chromosome 22 q11 deletion syndrome diagnosed in a 32-year-old man with hypoparathyroidism. Journal of Clinical Endocrinology and Metabolism 2004 89 4817-4820. (doi:10.1210/jc.2004-0442)

7 Kapadia CR, Kim YE, Donald-McGinn DM, Zackai EH \& Katz LE. Parathyroid hormone reserve in 22q11.2 deletion syndrome. Genetics in Medicine 200810 224-228. (doi:10.1097/GIM. Ob013e3181634edf)

8 Jawad AF, Donald-McGinn DM, Zackai E \& Sullivan KE. Immunologic features of chromosome 22q11.2 deletion syndrome (DiGeorge syndrome/velocardiofacial syndrome). Journal of Pediatrics 2001139 715-723. (doi:10.1067/mpd.2001.118534)

9 Gennery AR, Barge D, O’Sullivan JJ, Flood TJ, Abinun M \& Cant AJ. Antibody deficiency and autoimmunity in 22q11.2 deletion syndrome. Archives of Disease in Childhood $2002 \mathbf{8 6} 422-425$. (doi:10.1136/adc.86.6.422)

10 Kratz CP, Niehues T, Lyding S, Heusch A, Janssen G \& Gobel U. Evans syndrome in a patient with chromosome 22q11.2 deletion syndrome: a case report. Pediatric Hematology and Oncology 2003 20 167-172. (doi:10.1080/0880010390158685)

11 DePiero AD, Lourie EM, Berman BW, Robin NH, Zinn AB \& Hostoffer RW. Recurrent immune cytopenias in two patients with DiGeorge/velocardiofacial syndrome. Journal of Pediatrics 1997 131 484-486. (doi:10.1016/S0022-3476(97)80085-6)

12 Sullivan KE, Jawad AF, Randall P, Driscoll DA, Emanuel BS, McDonald-Mcginn DM \& Zackai EH. Lack of correlation between impaired T cell production, immunodeficiency, and other phenotypic features in chromosome 22q11.2 deletion syndromes. Clinical and Experimental Immunology 199886 141-146. (doi:10.1006/ clin.1997.4463)

13 Digilio MC, Giannotti A, Castro M, Colistro F, Ferretti F, Marino B \& Dallapiccola B. Screening for celiac disease in patients with deletion 22q11.2 (DiGeorge/velo-cardio-facial syndrome). American Journal of Medical Genetics. Part A 2003 121A 286-288. (doi:10.1002/ajmg.a.20254)

14 Piliero LM, Sanford AN, Donald-McGinn DM, Zackai EH \& Sullivan KE. T-cell homeostasis in humans with thymic hypoplasia due to chromosome 22q11.2 deletion syndrome. Blood 2004103 1020-1025. (doi:10.1182/blood-2003-08-2824)

15 Lima K, Abrahamsen TG, Foelling I, Natvig S, Ryder LP \& Olaussen RW. Low thymic output in the 22q11.2 deletion syndrome measured by CCR9CD45RA T cell counts and $\mathrm{T}$ cell receptor rearrangement excision circles. Clinical and Experimental Immunology 2010161 98-107. (doi:10.1111/j.1365-2249.2010.04152.x)

16 Sullivan KE, Donald-McGinn D \& Zackai EH. CD4 (+) CD25(+) T-cell production in healthy humans and in patients with thymic hypoplasia. Clinical and Diagnostic Laboratory Immunology 20029 1129-1131. (doi:10.1128/CDLI.9.5.1129-1131.2002)

17 Finocchi A, Di CS, Romiti ML, Capponi C, Rossi P, Carsetti R \& Cancrini C. Humoral immune responses and CD27+B cells in children with DiGeorge syndrome (22q11.2 deletion syndrome). Pediatric Allergy and Immunology 200617 382-388. (doi:10. 1111/j.1399-3038.2006.00409.x)

18 Smith CA, Driscoll DA, Emanuel BS, Donald-McGinn DM, Zackai EH \& Sullivan KE. Increased prevalence of immunoglobulin 
A deficiency in patients with the chromosome 22q11.2 deletion syndrome (DiGeorge syndrome/velocardiofacial syndrome). Clinical and Diagnostic Laboratory Immunology 19985 415-417.

19 Davies K, Stiehm ER, Woo P \& Murray KJ. Juvenile idiopathic polyarticular arthritis and IgA deficiency in the 22q11 deletion syndrome. Journal of Rheumatology 200128 2326-2334.

20 Kung SJ, Gripp KW, Stephan MJ, Fairchok MP \& McGeady SJ. Selective IgM deficiency and 22q11.2 deletion syndrome. Annals of Allergy, Asthma \& Immunology 200799 87-92. (doi:10.1016/ S1081-1206(10)60627-8)

21 Gavalas NG, Kemp EH, Krohn KJ, Brown EM, Watson PF \& Weetman AP. The calcium-sensing receptor is a target of autoantibodies in patients with autoimmune polyendocrine syndrome type 1. Journal of Clinical Endocrinology and Metabolism 200792 2107-2114. (doi:10.1210/jc.2006-2466)

22 Kemp EH, Gavalas NG, Krohn KJ, Brown EM, Watson PF \& Weetman AP. Activating autoantibodies against the calciumsensing receptor detected in two patients with autoimmune polyendocrine syndrome type 1. Journal of Clinical Endocrinology and Metabolism 2009 94 4749-4756. (doi:10.1210/jc.20091080)

23 Alimohammadi M, Björklund P, Hallgren A, Pöntynen N, Szinnai G, Shikama N, Keller MP, Ekwall O, Kinkel SA, Husebye ES, Gustafsson J, Rorsman F, Peltonen L, Betterle C, Perheentupa J, Åkerstrom G, Westin G, Scott HS, Holländer GA \& Kämpe O. Autoimmune polyendocrine syndrome type 1 and NALP5, a parathyroid autoantigen. New England Journal of Medicine 2008 358 1018-1028. (doi:10.1056/NEJMoa0706487)

24 Lima K, Folling I, Eiklid KL, Natvig S \& Abrahamsen TG. Agedependent clinical problems in a Norwegian national survey of patients with the 22q11.2 deletion syndrome. European Journal of Pediatrics 2010169 983-989. (doi:10.1007/s00431-010-1161-3)

25 Ahonen P, Myllarniemi S, Sipila I \& Perheentupa J. Clinical variation of autoimmune polyendocrinopathy-candidiasisectodermal dystrophy (APECED) in a series of 68 patients. New England Journal of Medicine 1990322 1829-1836. (doi:10. 1056/NEJM199006283222601)

26 Stray-Pedersen A, Jonsson T, Heiberg A, Lindman CR, Widing E, Aaberge IS, Borresen-Dale AL \& Abrahamsen TG. The impact of an early truncating founder ATM mutation on immunoglobulins, specific antibodies and lymphocyte populations in ataxiatelangiectasia patients and their parents. Clinical and Experimental Immunology 2004137 179-186. (doi:10.1111/j.1365-2249. 2004.02492.x)

27 Erlich H, Valdes AM, Noble J, Carlson JA, Varney M, Concannon P, Mychaleckyj JC, Todd JA, Bonella P, Fear AL, Lavant E, Louey A \& Moonsamy P. HLA DR-DQ haplotypes and genotypes and type 1 diabetes risk: analysis of the type 1 diabetes genetics consortium families. Diabetes 200857 1084-1092. (doi:10.2337/db07-1331)

28 Söderbergh A, Myhre AG, Ekwall O, Gebre-Medhin G, Hedstrand H, Landgren E, Mietinen A, Eskelin P, Halonen M, Tuomi T, Gustafsson J, Husebye ES, Perheentupa H, Gylling M, Manns MP, Rorsman F, Kämpe $\mathrm{O} \&$ Nilsson T. Prevalence and clinical associations of 10 defined autoantibodies in autoimmune polyendocrine syndrome type I. Journal of Clinical Endocrinology and Metabolism 200489 557-562. (doi:10.1210/jc.2003-030279)

29 Oftedal BE, Wolff AS, Bratland E, Kämpe O, Perheentupa J, Myhre AG, Meager A, Purushothaman R, Ten S \& Husebye ES. Radioimmunoassay for autoantibodies against interferon omega; its use in the diagnosis of autoimmune polyendocrine syndrome type I. Clinical Immunology 2008129 163-169. (doi:10.1016/j. clim.2008.07.002)

30 Skjaerven R, Gjessing HK \& Bakketeig LS. Birthweight by gestational age in Norway. Acta Obstetrica et Gynecologica Scandinavica $2000 \quad 79$ 440-449. (doi:10.1080/j.1600-0412. 2000.079006440.x)

31 Choi JH, Shin YL, Kim GH, Seo EJ, Kim Y, Park IS \& Yoo HW. Endocrine manifestations of chromosome 22q11.2 microdeletion syndrome. Hormone Research 200563 294-299. (doi:10.1159/ 000086745)
32 Moraes-Vasconcelos D, Costa-Carvalho BT, Torgerson TR \& Ochs HD. Primary immune deficiency disorders presenting as autoimmune diseases: IPEX and APECED. Journal of Clinical Immunology 200828 S11-S19. (doi:10.1007/s10875-0089176-5)

33 Jacob CM, Pastorino AC, Fahl K, Carneiro-Sampaio M \& Monteiro RC. Autoimmunity in IgA deficiency: revisiting the role of IgA as a silent housekeeper. Journal of Clinical Immunology 200828 S56-S61. (doi:10.1007/s10875-007-9163-2)

34 Prelog M, Keller M, Geiger R, Brandstatter A, Wurzner R, Schweigmann U, Zlamy M, Zimmerhackl LB \& GrubeckLoebenstein B. Thymectomy in early childhood: significant alterations of the $\mathrm{CD} 4(+) \mathrm{CD} 45 \mathrm{RA}(+) \mathrm{CD} 62 \mathrm{~L}(+)$ T cell compartment in later life. Clinical Immunology 2009130 123-132. (doi:10.1016/j.clim.2008.08.023)

35 Marin GG, Cardiel MH, Cornejo H \& Viveros ME. Prevalence of antinuclear antibodies in 3 groups of healthy individuals: blood donors, hospital personnel, and relatives of patients with autoimmune diseases. Journal of Clinical Rheumatology 200915 325-329. (doi:10.1097/RHU.0b013e3181bb971b)

36 Deane PM, Liard G, Siegel DM \& Baum J. The outcome of children referred to a pediatric rheumatology clinic with a positive antinuclear antibody test but without an autoimmune disease. Pediatrics $199595892-895$.

37 Husebye ES, Perheentupa J, Rautemaa R \& Kämpe O. Clinical manifestations and management of patients with autoimmune polyendocrine syndrome type I. Journal of Internal Medicine 2009 265 514-529. (doi:10.1111/j.1365-2796.2009.02090.x)

38 Erichsen MM, Løvas K, Skinningsrud B, Wolff AB, Undlien DE, Svartberg J, Fougner KJ, Berg TJ, Bollerslev J, Mella B, Carlson JA, Erlich H \& Husebye ES. Clinical, immunological, and genetic features of autoimmune primary adrenal insufficiency: observations from a Norwegian registry. Journal of Clinical Endocrinology and Metabolism 200994 4882-4890. (doi:10.1210/jc.20091368)

39 Coco G, Dal PC, Presotto F, Albergoni MP, Canova C, Pedini B, Zanchetta R, Chen S, Furmaniak J, Rees Smith B, Mantero F \& Betterle C. Estimated risk for developing autoimmune Addison's disease in patients with adrenal cortex autoantibodies. Journal of Clinical Endocrinology and Metabolism 200691 1637-1645. (doi:10.1210/jc.2005-0860)

40 Bassett AS, Chow EW, Husted J, Weksberg R, Caluseriu O, Webb GD \& Gatzoulis MA. Clinical features of 78 adults with 22q11 deletion syndrome. American Journal of Medical Genetics. Part A 2005138 307-313. (doi:10.1002/ajmg.a.30984)

41 Bjoro T, Holmen J, Kruger O, Midthjell K, Hunstad K, Schreiner T, Sandnes L \& Brochmann H. Prevalence of thyroid disease, thyroid dysfunction and thyroid peroxidase antibodies in a large, unselected population. The Health Study of Nord-Trondelag (HUNT). European Journal of Endocrinology 2000143 639-647. (doi:10.1530/eje.0.1430639)

42 Sullivan KE, Donald-McGinn DM, Driscoll DA, Zmijewski CM, Ellabban AS, Reed L, Emanuel BS, Zackai EH, Athreya BH \& Keenan G. Juvenile rheumatoid arthritis-like polyarthritis in chromosome 22q11.2 deletion syndrome (DiGeorge anomalad/ velocardiofacial syndrome/conotruncal anomaly face syndrome). Arthritis and Rheumatism 199740 430-436. (doi:10.1002/art. 1780400307)

43 Herwadkar A, Gennery AR, Moran AS, Haeney MR \& Arkwright PD. Association between hypoparathyroidism and defective $\mathrm{T}$ cell immunity in 22q11.2 deletion syndrome. Journal of Clinical Pathology 201063 151-155. (doi:10.1136/ jcp.2009.072074)

Received 6 May 2011

Accepted 23 May 2011 